into the dental chair unit and, secondly, suck back of patient's saliva into the line due to lack of anti-retraction valves. Even a small amount of Pseudomonas aeruginosa in a municipal water system can contribute to the dental chair unit contamination problem because dental chair units provide a different environment with small bores, narrow lumens and periods of stagnant water. However, if the water is well maintained according to current hygiene guidelines, the prevalence of Pseudomonas aeruginosa in the public water supply is extremely low [6]. As Pseudomonas aeruginosa can be recovered from the oral cavity of $\sim 4 \%$ of healthy individuals [7], it is therefore possible that some of these bacteria are aspirated into the dental chair unit waterlines through a defective check valve and are able to colonise in the waterlines. As the suction system hoses and pipe work are frequently wet, they provide an environment that is conducive to the growth and proliferation of biofilms which adhere to the inner surfaces of the lines. This biofilm protects the bacteria both from being washed away by the water flow and from many types of antimicrobial water treatment [8].

\section{J. Barben* and J. Schmid}

*Dept of Paediatric Pulmonology and CF Centre, Children's Hospital, and "Public Health and Consumer Protection Agency, St. Gallen, Switzerland.

\section{STATEMENT OF INTEREST}

None declared.

\section{REFERENCES}

1 Schelstraete P, Van Daele S, De Boeck K, et al. Pseudomonas aeruginosa in the home environment of newly infected cystic fibrosis patients. Eur Respir J 2008; 31: 822-829.

2 Exner M, Haun F, Kocikowski R. Zahnärztliche Einheiten als Kontaminationsquelle für Pseudomonas aeruginosa. [Dental units as sources of contamination by Pseudomonas aeruginosa]. Dtsch Zahnarztl Z 1981; 36: 819-824.

3 Barbeau J, Gauthier C, Payment P. Biofilms, infectious agents, and dental unit waterlines: a review. Can J Microbiol 1998; 44: 1019-1028.

4 Walker JT, Bradshaw DJ, Bennett AM, Fulford MR, Martin MV, Marsh PD. Microbial biofilm formation and contamination of dental-unit water systems in general dental practice. Appl Environ Microbiol 2000; 66: 3363-3367.

5 Kohn WG, Collins AS, Cleveland JL, et al. Guidelines for infection control in dental health-care settings - 2003 MMWR Recomm Rep 2003; 52: 1-61.

6 Barben J, Hafen G, Schmid J, Swiss Paediatric Respiratory Research Group. Pseudomonas aeruginosa in public swimming pools and bathroom water of patients with cystic fibrosis. J Cyst Fibros 2005; 4: 227-231.

7 Botzenhart K, Puhr OF, Döring G. [Pseudomonas aeruginosa in the oral cavity; occurance and age distribution of adult germ carriers.]. Zentralbl Bakt Mikrobiol 1985; 180: 471-479.

8 Donlan RM. Biofilms: microbial life on surfaces. Emerg Infect Dis 2002; 8: 881-890.

DOI: $10.1183 / 09031936.00072808$

\title{
Impact of poor dental health on pneumonia
}

\section{To the Editors:}

Pneumonia imposes a significant burden on a population, not only in terms of morbidity and mortality but also economically [1-3]. Direct costs generally increase from community-acquired pneumonia (CAP; US\$25,218), healthcare-associated pneumonia (HCAP; US $\$ 27,647$ ), hospital-acquired pneumonia (HAP; US $\$ 65,292)$ to ventilator-associated pneumonia (US\$150,841) and reflect the level of care and length of hospitalisation [1]. The prevalence of elderly patients with pneumonia admitted to hospital is rising and it has been suggested that greater effort is required to vaccinate these individuals and identify other comorbid factors [4]. Even amongst employed patients with CAP, the majority of direct costs (59\%) are attributable to a small proportion of individuals $(10 \%)$ who require hospitalisation [2]. COLICE et al. [3] estimated that even amongst working individuals, the annual cost of CAP in the USA amounted to US\$12.2 billion in 2004 .

It was therefore with great interest that we read the study by ALMIRALL et al. [5], which attempted to identify new modifiable risk factors for CAP in a general population. Uniquely for a study of CAP, the authors chose to look at indices of dental health status and found that a visit to the dentist in the previous month was protective, while dental dysaesthesia or wearing a dental prosthesis were risk factors for CAP. These associations existed even though previously identified risk factors in larger populations of CAP, such as the use of acidsuppressing drugs, were not apparent [6].

There is an accumulating body of data that implicates dental plaque as a reservoir for pulmonary infection in critical care and institutionalised elderly patients [7], and that even instituting a programme of dental hygiene can reduce episodes of HCAP [8]. The study by ALMIRALL et al. [5] has important implications for healthcare resources, particularly in the UK where there have been numerous media reports detailing patients' difficulty in accessing dental care. THOMAs et al. [9] recently analysed data on all hospital admissions in England for dental abscess drainage and found a doubling of admissions between 1998-1999 and 2005-2006. Concurrently, the number of patients registered with a National Health Service (NHS) dentist has fallen by 6 million between 1994 and 2004; more than a fifth of patients in a recent survey had declined dental treatment because of cost [9]. Provision of NHS dentists compares poorly with other European countries and is unevenly distributed, such that a quarter of the population of England and Wales are supplied with $<0.3$ NHS dentists per 
1,000 people [10]. Indeed, hospital admissions for drainage of dental abscesses showed the greatest increase in socially disadvantaged areas [11].

We would suggest that poor access to dental care, particularly in deprived areas of the UK where other risk factors for community acquired pneumonia coexist, is likely to increase the burden of pneumonia and place further pressure on limited healthcare resources. In addition, dental services within hospitals and long-term care institutions need to improve as they are woefully inadequate in their current form and provide little more than a service to extract loose or severely decayed teeth. Investment in General Dental Services in the UK amounts to $<2 \%$ of the NHS budget, even in our own institution the funds for the entire Dental School is less than the Critical Care Unit. Oral health needs to be established as a priority not only in the community but also for hospital patients or institutionalised adults in much the same way as deep-vein thrombosis prophylaxis. Investment in promotion of oral hygiene is likely to prove an extremely cost-effective long-term measure.

M.P. Wise*, D.W. Williams", M.A. Lewis", J.G. Thomas ${ }^{\star}$ and P.J. Frost*

*Adult Critical Care, University Hospital of Wales, "Dept of Oral Surgery, Medicine and Pathology, Cardiff University, Dental School, Cardiff, UK, and "Depts of Pathology and Periodontics, West Virginia University Schools of Medicine and Dentistry, Morgantown, WV, USA.

\section{STATEMENT OF INTEREST}

A statement of interest for M.A. Lewis can be found at www.erj.ersjournals.com $/$ misc/statements.shtml

\section{REFERENCES}

1 Kollef MH, Shorr A, Tabak YP, Gupta V, Liu LZ, Johannes RS. Epidemiology and outcomes of health-care-associated pneumonia: results from a large US database of culture-positive pneumonia. Chest 2005; 128: 3854-3862.

2 Birnbaum HG, Morley M, Greenberg PE, Cifaldi M, Colice GL. Economic burden of pneumonia in an employed population. Arch Intern Med 2001; 161: 2725-2731.

3 Colice GL, Morley MA, Asche C, Birnbaum HG. Treatment costs of community acquired pneumonia in an employed population. Chest 2004; 125: 2140-2145.

4 Fry AM, Shay DK, Holman RC, Curns AT, Anderson LJ. Trends in hospitalizations for pneumonia among persons aged 65 years or older in the United States, 1988-2002. JAMA 2005; 294: 2712-2719.

5 Almirall J, Bolíbar I, Serra-Prat M, et al. New evidence of risk factors for community-acquired pneumonia: a population-based study. Eur Respir J 2008; 31: 1274-1284.

6 Laheij RJ, Sturkenboom MC, Hassing RJ, Dieleman J, Stricker BH, Jansen JB. Risk of community-acquired pneumonia and use of gastric acid-suppressive drugs. JAMA 2004; 292: 1955-1960.

7 Paju S, Scannapieco FA. Oral biofilms, periodontitis, and pulmonary infections. Oral Dis. 2007; 13: 508-512.

8 Adachi M, Ishihara K, Abe S, Okuda A, Ishikawa T. Effect of professional oral health care on the elderly living in nursing homes. Oral Surg Oral Med Oral Pathol Oral Radiol Endod 2002; 94: 191-195.

9 Thomas SJ, Atkinson C, Hughes C, Revington P, Ness AR. Is there an epidemic of admissions for surgical treatment of dental abscesses in the UK? BMJ 2008; 336: 1219-1220.

10 Boulos MN, Phillipps GP. Is NHS dentistry in crisis? "Traffic light" maps of dentists distribution in England and Wales. Int J Health Geogr 2004; 3: 10.

11 Moles DR. Epidemic of dental abscesses?: Dental abscesses have increased most among poorer people. BMJ 2008; 336: 1323.

\section{Reproducibility of exhaled breath condensate markers}

\section{To the Editors:}

The letter by Rosias et al. [1] highlights that individual biomarkers in exhaled breath condensate (EBC) require specific methods for optimal collection. Denominators need to be determined (such as time, total breath collection, protein, electrolytes, conductivity or other more stable markers) and, critically, researchers should consider collecting whole or global EBC, which may enhance reproducibility.

To determine the reproducibility of simple ions and more complex molecules, such as proteins and eicosanoids in different disease categories, we used the EcoScreen ${ }^{\circledR}$ (Erich Jaeger $\mathrm{GmbH}$, Hochberg, Germany) to study the within-day variability of EBC biomarkers from 11 subjects with asbestosis, 14 with pulmonary fibrosis (PF) and 22 healthy normal subjects (tables 1 and 2).
Two EBC samples, obtained over exactly $10 \mathrm{~min}$, were collected on the same day from each subject at 09:00 $\mathrm{h}$ and 13:00 $\mathrm{h}$. The mean \pm SD EBC volumes collected at 09:00 $\mathrm{h}$ and 13:00 h were similar $(1,831 \pm 498$ versus $1,831 \pm 586 \mu \mathrm{L})$. The coefficient of variation $(\mathrm{CV})$ for within-day EBC volume for all subjects was $14.8 \%$. The mean CV for within-day EBC volume was increased at $23.0 \%$ in subjects with $\mathrm{PF}$, possibly due to their more severe, restrictive lung function. Patients with PF had significantly reduced forced expiratory volume in one second (\% predicted) and forced vital capacity (\% pred) compared with normal subjects $(73.2 \pm 17.7$ versus $97.1 \pm 14.7$ and $72.9 \pm 17.5$ versus $98.7 \pm 13.1$ at $09: 00 \mathrm{~h}$ and $13: 00 \mathrm{~h}$, respectively; both $\mathrm{p}<0.0001$, ANOVA and multiple comparison post hoc tests) and those with asbestosis (73.2 \pm 17.7 versus $83.2 \pm 14.2(p=0.14)$ and $72.9 \pm 17.5$ versus $85.3 \pm 16.8(p=0.09)$, respectively). 